\title{
e-Migrinter
}

$20 \mid 2020$

Hospitalité et migration

\section{Trouver refuge dans les Cévennes, un réseau d'accueil dessiné entre les lignes de crêtes}

\section{Élise Martin}

\section{(2) OpenEdition}

\section{Journals}

Édition électronique

URL : https://journals.openedition.org/e-migrinter/2316

DOI : 10.4000/e-migrinter.2316

ISSN : 1961-9685

Éditeur

UMR 7301 - Migrinter

Référence électronique

Élise Martin, «Trouver refuge dans les Cévennes, un réseau d'accueil dessiné entre les lignes de crêtes », e-Migrinter [En ligne], 20 | 2020, mis en ligne le 23 juillet 2020, consulté le 20 mai 2021. URL : http://journals.openedition.org/e-migrinter/2316 ; DOI : https://doi.org/10.4000/e-migrinter.2316

Ce document a été généré automatiquement le 20 mai 2021.

Tous droits réservés 


\title{
Trouver refuge dans les Cévennes, un réseau d'accueil dessiné entre les lignes de crêtes
}

\author{
Élise Martin
}

\begin{abstract}
Il existe une autre France, une autre Europe, un autre Monde. Malgré les discours et un procès contemporain permanent contre les émotions, la sensibilité et les humanismes qui leur sont liés, il existe des milliers de dispositions et de pratiques qui organisent une cité sensible, permettent à la

démocratie d'exister dans tous les quartiers, créant un monde de voisins. Leur place est sousévaluée dans la vie publique alors qu'elle s'avère centrale (Brugère, Le Blanc, 2017).
\end{abstract}

Cet autre monde, cette autre France s'illustre quotidiennement dans des grandes métropoles françaises et européennes comme le montre l'abondante littérature scientifique qui porte sur l'accueil d'exilés en milieu urbain. De fait, les chercheurs en sciences sociales se questionnent sur la place des exilés dans la ville et la façon dont ils tentent de se l'approprier (Dahdah et al., 2018 ; Brault, et al., 2018 ; Belmessous, Roche, 2018) et s'intéressent aux dynamiques qui font de la ville une ville accueillante ou un refuge (Hanappe, 2018 ; Boudou, 2018), impulsées par des acteurs de la société civile et des collectifs de citoyens engagés (Louis, 2017 ; Babels, 2019), ou, à une autre échelle, par les maires et élus de grandes métropoles (Babels, 2018). En miroir, la littérature qui porte sur l'accueil des étrangers en milieu rural semble moins dense. Les espaces ruraux français situés en dehors des aires d'influence des grandes métropoles sont pourtant maillés de réseaux d'associations et de solidarité qui permettent aux exilés de faire une pause dans leur parcours et de reprendre leur souffle (Martin, 2020). Le territoire de l'exil n'étant pas un territoire figé (Tarrius, 2014), les personnes exilées circulent, sont amenées à traverser ces territoires ruraux et à s'y installer temporairement. C'est le cas de l'arrière-pays languedocien et des Cévennes gardoises 
(voir tableau 1 et carte 1), souvent citées comme des terres d'accueil historiques ${ }^{1}$. L'étude qui suit a pour but d'analyser le fonctionnement de cet espace qui est aujourd'hui le lieu d'un système d'hospitalité - soit la propension des habitants d'un territoire à se fédérer dans le but d'accueillir pour une durée indéterminée des personnes qui en éprouveraient le besoin - qui fonctionne à plein. Comment s'organise l'accueil dans un espace de moyenne montagne, à quelle échelle ? Qui sont les acteurs de l'hospitalité ? Sur quelles structures sociales et religieuses peuvent-ils compter? Autant de pistes que l'article tente d'explorer à travers une approche multiscalaire des réseaux de solidarité de l'arrière-pays gardois. Pour ce faire, l'étude s'appuie sur des entretiens et observations (lors de réunions de collectifs, rassemblements, manifestations, dans des cafés, lors de marchés) réalisés en mars et avril 2017 et mars 2019 dans les villes et villages du Vigan, de Monoblet, de Saint-Jean-du-Gard, de Lasalle, de Mialet et de Génolhac. La plupart des entretiens utilisés dans l'article datent de 2017.

Tableau 1 : Liste des entretiens et observations utilisés dans l'article

\begin{tabular}{|c|c|c|}
\hline & Personne interrogée & Date et lieu de l'entretien \\
\hline $\begin{array}{l}\text { Entretien } \\
1\end{array}$ & Maire de Lasalle & 20 mars 2017 à Lasalle \\
\hline $\begin{array}{l}\text { Entretien } \\
2\end{array}$ & Maire de Saint-Jean-du-Gard & 3 avril 2017 à Saint-Jean-du-Gard \\
\hline $\begin{array}{l}\text { Entretien } \\
3\end{array}$ & $\begin{array}{l}\text { Josiane et Pascal, membres du collectif Pays } \\
\text { Viganais Terre d'Accueil }\end{array}$ & 23 mars 2017 au Vigan \\
\hline $\begin{array}{l}\text { Entretien } \\
4\end{array}$ & Nadine, présidente d'Abraham Mazel & 22 mars 2017 à Saint-Jean-du-Gard \\
\hline $\begin{array}{l}\text { Entretien } \\
5\end{array}$ & $\begin{array}{l}\text { Manu, membre d'un groupe de militants qui } \\
\text { soutient les exilés à Saint-Jean-du-Gard }\end{array}$ & 3 avril 2017 à Saint-Jean-du-Gard \\
\hline $\begin{array}{l}\text { Entretien } \\
6\end{array}$ & $\begin{array}{l}\text { Nathalie, membre du collectif Solidarité migrants } \\
\text { Cévennes de Saint-Jean-du-Gard }\end{array}$ & 10 mars 2017 à Saint-Jean-du-Gard \\
\hline $\begin{array}{l}\text { Entretien } \\
7\end{array}$ & Martine, accueillante & $\begin{array}{l}29 \text { mars } 2017 \text { dans la maison de } \\
\text { Martine, isolée dans la montagne }\end{array}$ \\
\hline $\begin{array}{l}\text { Entretien } \\
8\end{array}$ & $\begin{array}{l}\text { Suzanne, membre du collectif Solidarité Lasalle- } \\
\text { en-Cévennes }\end{array}$ & 31 mars 2017 à Lasalle \\
\hline
\end{tabular}

Réalisation : Élise Martin, 2020

\section{Répondre collectivement à l'appel}

2 Jusqu'en 2015, l'accueil de personnes exilées en Cévennes était limité à quelques villages. Il s'agissait d'un fait relativement isolé, peu médiatisé et peu revendiqué. Depuis les images du cadavre d'Aylan Kurdi sur une plage turque (septembre 2015) et le 
démantèlement des jungles de Calais et Paris (octobre et novembre 2016), l'accueil s'est intensifié et concerne désormais une dizaine de communes du nord du Gard. Cette propension à accueillir témoigne d'une volonté de répondre à l'urgence humanitaire dans laquelle se trouve un grand nombre de personnes exilées en France mais aussi d'un rejet grandissant des politiques migratoires menées par les gouvernements français et européens. L'accueil qui a lieu en Cévennes traduit à la fois une réaction émotionnelle, une "réponse involontaire à la vulnérabilité des vies invivables" (Brugère, Le Blanc, 2017) et un engagement politique croissant des habitants de ce territoire.

\section{Le collectif accueillant, premier chainon du système de solidarité cévenol}

3 Le nord du Gard est maillé de villes et villages qui accueillent des personnes en exil que l'on peut organiser en plusieurs catégories (voir tableau 2 et carte 1).

Carte 1 : Les Cévennes, un massif de moyenne montagne au cœur d'un réseau d'accueil

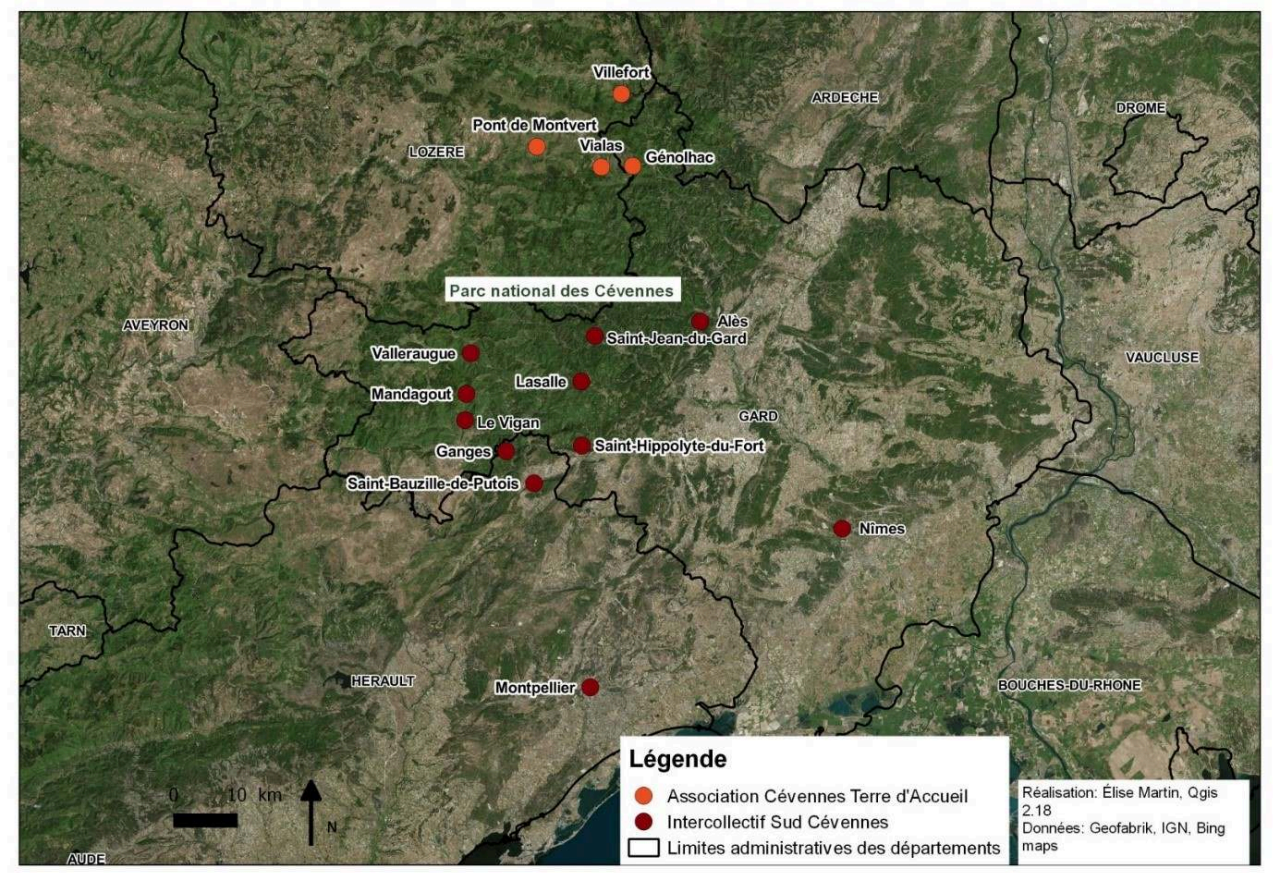

Réalisation : Élise Martin, 2020

4 Un premier groupe est constitué des villes les plus densément peuplées comme Ganges, Saint-Hippolyte-du-Fort, Le Vigan, Saint-Jean-du-Gard et Saint-Bauzille-de-Putois. Celles-ci proposent une gamme complète de services et sont assez bien connectées au reste du territoire régional. Ganges et Saint-Hippolyte-du-Fort sont des pôles urbains situés sur un axe routier est-ouest qui longe les contreforts cévenols par le sud, et se trouvent à équidistance de Nîmes et Montpellier (à $1 \mathrm{~h}$ de route environ des deux villes). Le Vigan et Saint-Jean-du-Gard, quant à eux, sont les principaux pôles urbains du sud des Cévennes et font le lien entre le piémont cévenol et les villages situés dans la 
montagne $e^{2}$. La commune de Saint-Bauzille-de-Putois, plus petite, se situe aux pieds des Cévennes, au sud de Ganges sur la route de Montpellier.

5 Des collectifs accueillants se sont également formés dans des villages moins denses et plus retirés comme Lasalle, Valleraugue ou Génolhac (trois villages-rues) et même dans des localités encore plus petites, comme Mandagout, Pont-de-Montvert, Villefort ou Vialas.

Tableau 2 : Villes et villages accueillant des personnes exilées dans les Cévennes et collectifs formés depuis $2015^{3}$

\begin{tabular}{|c|c|c|c|}
\hline $\begin{array}{l}\text { Nom de la } \\
\text { commune } \\
\text { (nombre } \\
\text { d'habitants*) }\end{array}$ & $\begin{array}{l}\text { Profil des personnes } \\
\text { accueillies depuis } 2015 \text { et } \\
\text { modalités de l'accueil }\end{array}$ & Nom du collectif & $\begin{array}{l}\text { Appartenance à un } \\
\text { intercollectif ou une } \\
\text { association }\end{array}$ \\
\hline $\begin{array}{l}\text { Ganges } \\
\text { (4024 habitants) }\end{array}$ & $\begin{array}{l}\text { Familles accueillies par des } \\
\text { habitants (dont une famille } \\
\text { géorgienne) }\end{array}$ & $\begin{array}{l}\text { Collectif } \quad \text { Ganges } \\
\text { Solidarité }\end{array}$ & \multirow{8}{*}{$\begin{array}{l}\text { Intercollectif Sud- } \\
\text { Cévennes }\end{array}$} \\
\hline $\begin{array}{l}\text { Saint-Hyppolite- } \\
\text { du-Fort } \\
\text { (3939 habitants) }\end{array}$ & $\begin{array}{l}\text { Familles accueillies par des } \\
\text { habitants (algériennes et } \\
\text { albanaises) et jeunes hommes } \\
\text { en CAO** }\end{array}$ & $\begin{array}{l}\text { Collectif Solidarité } \\
\text { Réfugiés Cigalois }\end{array}$ & \\
\hline $\begin{array}{l}\text { Le Vigan } \\
\text { (3820 habitants) }\end{array}$ & $\begin{array}{l}\text { Vingt jeunes hommes accueillis } \\
\text { en CAO (pour la plupart } \\
\text { soudanais) }\end{array}$ & $\begin{array}{lr}\text { Collectif } & \text { Pays } \\
\text { Viganais } & \text { Terre } \\
\text { d'Accueil } & \end{array}$ & \\
\hline $\begin{array}{l}\text { Saint-Jean-du- } \\
\text { Gard } \quad(2433 \\
\text { habitants })\end{array}$ & $\begin{array}{l}\text { Deux familles accueillies (dont } \\
\text { une famille tchétchène) }\end{array}$ & $\begin{array}{l}\text { Collectif Solidarité } \\
\text { Migrants Cévennes }\end{array}$ & \\
\hline $\begin{array}{l}\text { Saint-Bauzille-de- } \\
\text { Putois } \\
\text { (1977 habitants) }\end{array}$ & $\begin{array}{l}\text { Quarante hommes accueillis en } \\
\text { CAO }\end{array}$ & $\begin{array}{l}\text { Collectif Accueil en } \\
\text { Cévennes }\end{array}$ & \\
\hline $\begin{array}{l}\text { Lasalle } \\
\text { (1140 habitants) }\end{array}$ & $\begin{array}{l}\text { Deux familles afghanes } \\
\text { accueillies par des habitants et } \\
\text { huit jeunes hommes en CAO** } \\
\text { (pour la plupart afghans) }\end{array}$ & $\begin{array}{l}\text { Collectif Solidarité } \\
\text { Lasalle-en-Cévennes }\end{array}$ & \\
\hline $\begin{array}{l}\text { Valleraugue } \\
\text { (1051 habitants) }\end{array}$ & $\begin{array}{l}\text { Une famille albanaise accueillie } \\
\text { par des habitants }\end{array}$ & $\begin{array}{l}\text { Collectif Accueillir ̀̀ } \\
\text { Valleraugue }\end{array}$ & \\
\hline $\begin{array}{l}\text { Mandagout } \\
\text { (401 habitants) }\end{array}$ & $\begin{array}{l}\text { Une famille syrienne accueillie } \\
\text { par des habitants }\end{array}$ & $\begin{array}{l}\text { Collectif Bienvenue ̀̀ } \\
\text { Mandagout }\end{array}$ & \\
\hline $\begin{array}{l}\text { Monoblet } \\
\text { (728 habitants) }\end{array}$ & $\begin{array}{l}\text { Trente jeunes hommes } \\
\text { accueillis en CAOMI** (pour la } \\
\text { plupart afghans) }\end{array}$ & $* * *$ & \\
\hline
\end{tabular}




\begin{tabular}{|c|c|c|c|}
\hline $\begin{array}{l}\text { Génolhac } \\
\text { (841 habitants) }\end{array}$ & $\begin{array}{l}\text { Personnes isolées et familles } \\
\text { accueillies par des habitants }\end{array}$ & Collectif de Génolhac & \multirow{4}{*}{ Cévennes Terre d'Accueil } \\
\hline $\begin{array}{l}\text { Pont-de-Montvert } \\
\text { (548 habitants) }\end{array}$ & $\begin{array}{l}\text { Familles accueillies par des } \\
\text { habitants }\end{array}$ & $\begin{array}{l}\text { Collectif de Pont-de- } \\
\text { Montvert }\end{array}$ & \\
\hline $\begin{array}{l}\text { Villefort } \\
\text { (548 habitants) }\end{array}$ & $\begin{array}{l}\text { Familles accueillies par des } \\
\text { habitants }\end{array}$ & Collectif de Villefort & \\
\hline $\begin{array}{l}\text { Vialas } \\
\text { (432 habitants) }\end{array}$ & $\begin{array}{l}\text { Familles accueillies (dont une } \\
\text { famille kurde irakienne) par } \\
\text { des habitants }\end{array}$ & Collectif de Vialas & \\
\hline
\end{tabular}

* Nombre d'habitants en 2017 d'après I'INSEE

** Le CAOMI de Monoblet et les CAO de Saint-Hyppolite-du-Fort, du Vigan et de Lasalle étaient gérés par la même association gestionnaire. En 2020, seuls les CAO de Saint-Hyppolite-du-Fort et du Vigan continuent d'exister. Le CAOMI de Monoblet a fermé en février 2017 et le CAO de Lasalle en février 2018.

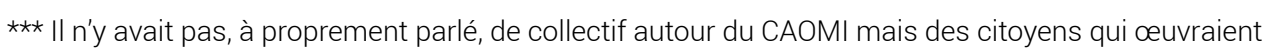
de manière isolée autour des jeunes hommes.

Réalisation : Élise Martin, 2020

6 La plupart des collectifs qui accueillent des personnes exilées dans des communes cévenoles sont nés au cours des années 2015, 2016 et 2017. Les personnes (rarement plus de 4 ou 5 individus) commencent par réfléchir à la faisabilité de l'accueil, cherchent un logement disponible et des associations actives et aptes à les soutenir. Une fois l'accueil acté, des exilés (surtout des personnes en demande d'asile) arrivent en Cévennes envoyés par des associations ou collectifs situés dans les villes les plus proches (Alès, Nîmes, Montpellier) ou en région parisienne. Ils sont logés dans la maison d'un membre du groupe, dans un logement rénové par la mairie de la commune concernée ou dans un bâtiment appartenant à la communauté protestante. L'accueil des migrants dans les villages parcourus suit souvent la même chronologie: les bénévoles pourvoient d'abord aux besoins immédiats des individus (nourriture, vêtements) puis organisent le quotidien (inscription des enfants à l'école, organisation des cours de français pour les parents, inscription dans différentes associations). La décision d'accueillir échoit aux citoyens engagés qui n'attendent pas forcément l'aval des instances municipales. Le positionnement des mairies varie d'ailleurs en fonction des villages. Si à Lasalle par exemple, le maire est partie prenante de l'accueil et revendique la tradition d'accueil qui ne s'est jamais démentie (entretien 1) ${ }^{4}$, à Saint-Jean-duGard, le maire s'y oppose et ne semble pas s'intéresser aux personnes accueillies. Il est assez opposé à ça, et considère qu'on a assez de malheur en France pour pas aller accueillir les autres (entretien 2).

7 Les collectifs citoyens accompagnent et logent des individus isolés et des familles mais viennent aussi apporter un soutien aux individus pris en charge via des dispositifs étatiques comme le dispositif $\mathrm{CAO}^{5}$ (Centre d'Accueil et d'Orientation) déployé dans tout le territoire français, notamment dans certains espaces ruraux.

Les CAO ont été médiatisés au moment de la destruction de la jungle de Calais puisque c'est dans ces centres que les personnes exilées évacuées ont été prises en 
charge. L'État a sélectionné des villes et villages qui possédaient des bâtiments vides d'une taille importante (anciennes colonies de vacances, anciens établissements-médico-sociaux et hôpitaux) pour y implanter ce dispositif. Les CAO ont été propulsés dans les territoires dans une certaine impréparation, les exilés ne sachant pas où ils allaient être emmenés et les habitants ne connaissant rien du profil des futurs accueillis. Cette installation rapide du dispositif a parfois freiné l'insertion des exilés dans les espaces d'accueil. Encore aujourd'hui, les contours de ce dispositif restent flous. Certains CAO sont implantés dans des communes depuis plus de trois ans, alors qu'il s'agissait à l'origine d'un dispositif temporaire de prise en charge.

Des établissements de ce type ont été mis en place dès la fin de l'année 2015 dans les communes cévenoles du Vigan, de Saint-Hippolyte-du-Fort ou encore de Monoblet $^{6}$. Les entretiens menés avec des membres de différents collectifs montrent la difficulté à articuler son action avec des associations mandatées par l'État (Masson Diez, 2018). À Monoblet où a été installé un CAOMI (Centre d'Accueil et d'Orientation pour Mineurs Isolés) entre octobre 2016 et mars 2017, des conflits ont éclaté entre des salariés de l'association gestionnaire et certains militants qui voulaient ouvrir le lieu vers l'extérieur (Martin, 2020). Pour pallier certaines difficultés à pénétrer les dispositifs CAO, certains collectifs mettent en place un accompagnement hors de la structure d'accueil. C'est le cas au Vigan où les bénévoles ont décidé de sortir les exilés du CAO. Ceux-ci tiennent des permanences dans un café associatif de la ville pour y donner des cours de français ou apporter une aide juridique :

Sur les activités on est assez libres [...]. L'ambigüité des relations avec [l'association gestionnaire], c'est qu'elle agit pour le compte de l'Etat donc dès qu'on veut toucher un peu au domaine juridique là on commence à être sur la ligne jaune, parce que [l'association gestionnaire] ne souhaite pas vraiment qu'on mette trop notre nez làdedans [...]. Par exemple pour avoir la liste officielle des noms, quand est-ce qu'ils ont rendez-vous à l'OFPRA, quand est-ce qu'ils sont passés au guichet unique, etc., ça va être très difficile d'avoir un tableau, sous prétexte de secret professionnel (entretien $3)$.

9 Les exilés s'y rendent régulièrement, ce qui contribue d'ailleurs à les rendre plus visibles dans la commune. Les collectifs, comme celui de Vigan ou celui qui s'est constitué à Lasalle autour de jeunes Afghans (Martin, 2020) sont aussi d'une aide précieuse après la sortie du CAO. Les accueillants parviennent à maintenir une réelle continuité dans l'accompagnement. Le travail de terrain et le suivi des collectifs sur le long terme permettent d'affirmer que les habitants des vallées aident les exilés à trouver un emploi, un stage ou encore un travail temporaire, même une fois que les personnes ne résident plus dans les Cévennes.

Les collectifs soutiennent également des personnes dans une situation administrative délicate (déboutées de l'asile, qui ont obtenu un refus de titre de séjour). En communiquant à travers les réseaux de collectifs, ils parviennent à trouver des solutions d'hébergement chez l'habitant (Gerbier-Aublanc, 2018, Gerbier-Aublanc, Masson Diez, 2019) dans le Gard ou dans d'autres départements.

11 La formation d'un "collectif autodéclaré » (Masson-Diez, 2018) suit souvent la même logique. Les personnes s'engagent dans le collectif de façon intentionnelle, impulsant la création d'un groupe ou en y adhérant (Gilbert, 1989; Searle, 1995 ; Kaufman, 2010) 
puis le collectif s'agrandit pour former un groupe plus important ${ }^{7}$. Les individus qui le forment se répartissent des tâches précises (accompagner aux rendez-vous médicaux, faire le suivi administratif, donner des cours de français) et se sentent assez libres de moduler leur implication. L'enquête de terrain montre le fonctionnement horizontal des collectifs. Il est rare qu'une figure unique se détache du groupe.

La plupart des groupes de soutien aux exilés dans les Cévennes se désignent comme des collectifs (voir tableau 2). Certains se sont donnés un nom ${ }^{8}$, d'autres adjoignent simplement le nom du village au collectif.

\section{Des coopérations inattendues : l'exemple de Saint-Jean-du-Gard}

Alors que la plupart des collectifs des villes et villages cévenols reposent sur des citoyens isolés qui s'entendent derrière un message commun, des collectifs peuvent parfois intégrer des associations déjà constituées. C'est le cas dans la petite ville de Saint-Jean-du-Gard.

14 L'accueil de familles à Saint-Jean-du-Gard a été impulsé en février 2016 lors d'une réunion autour de la question de l'exil menée par le coordinateur du réseau ANAIS ${ }^{9}$, réseau d'associations impliquées dans l'aide sociale, notamment auprès de personnes migrantes. La réunion qui a rassemblé pas loin de 80 personnes a abouti à la constitution du collectif Solidarité migrants Cévennes. Ce groupe repose sur plusieurs associations et structures que l'on peut qualifier de partenaires. Les deux principaux, qui constituent d'ailleurs un vivier de bénévoles, sont l'association Abraham Mazel et le groupe de militants Cévennes sans frontières, deux ensembles d'individus aux profils sociologiques différents.

L'association Abraham Mazel a été créée en 1992 par un groupe d'habitants ${ }^{10}$ à la suite du mouvement de contestation d'un projet de construction de barrage sur le Gardon de Mialet (Clavairolle, 2011). La question du rapport à l'étranger est au cœur des réflexions de l'association qui milite contre les injustices sociales et environnementales:

«l'association Abraham Mazel est une association laïque qui entend faire de la Maison Mazel ${ }^{11}$ un centre de réflexion et d'action destiné à mettre en valeur toutes les résistances aussi bien culturelles, économiques, écologiques pour proposer un territoire où l'homme et la nature sont en accord $»^{12}$.

La participation de l'association à l'accueil des familles de Saint Jean-du-Gard a tout de suite semblé une évidence pour les adhérents et les membres actifs. Il s'agit pour eux d'une forme de résistance qui se situe dans le prolongement des luttes passées.

Le groupe de militants, quant à lui, est un collectif informel créé en 2015 par des individus majoritairement jeunes, revenant du camp No border de Vintimille (Barone, 2018) ${ }^{13}$. Qu'est-ce qu'on pouvait faire dans les Cévennes sachant qu'on n'est très clairement pas un axe de passage? (entretien 5). C'est en se posant cette question que quelques individus ont décidé de former un groupe dont l'objectif principal est de réfléchir autour de la notion de frontière, de l'arrivée massive de réfugiés et de la crise migratoire (entretien 5). Pour ces militants, soutenir et accueillir des exilés localement est une action parmi d'autres, qu'il convient d'inclure dans une lutte plus large contre les frontières :

«Si les Cévennes sont géographiquement éloignées des points de crispation (comme Vintimille, Calais ou Marseille), les frontières se matérialisent partout. Des exilée.e.s sont déporté.e.s et enfermé.e.s dans des centres de rétention comme à 
Nîmes. Aux alentours d'Alès, des familles expulsées des centres d'hébergement sont accueillies par des personnes solidaires $»^{14}$.

\section{fonctionnement assez libre comme en témoignent ces propos tenus par un des} membres :

On s'est donné un nom pour avoir une adresse mail en gros, c'était plus simple d'avoir un minimum d'identité mais on s'en fout, on n'a jamais cherché à faire un collectif pour faire un collectif on s'en fout, on veut que chacun puisse prendre sa place et du coup c'est ce qui nous paraît le plus pertinent, qu'y a des personnes qui puissent s'investir et puis qui puissent prendre des initiatives, ça va des personnes qui vont toujours être sur les mobilisations, qui vont être vraiment porteuses ou les personnes qui vont juste s'investir sur une cantine, qui vont juste filer un petit coup de main de temps en temps, juste relire un tract, faire une banderole ou j'sais pas quoi, ou héberger après ça empêche pas qu'on s'voit, qu'on discute des choses ensemble mais $d u$ coup $v u$ les contraintes ...on a pas envie non plus d'un fonctionnement plus lourd, évidemment qu'on s'écoute, si y a un truc qui l'fait pas on s'le dit, mais on veut que ce soit assez souple, le but c'est pas de faire une administration quoi (entretien 5).

L'enquête de terrain montre une bonne entente entre les différents sous-groupes du collectif Solidarité migrants Cévennes, malgré quelques divergences. Au moment d'accueillir par exemple, tout le monde était d'accord pour ne pas choisir les familles ou du moins leur origine mais un conflit a éclaté sur la forme que devait prendre l'hébergement. Le groupe de militants proposait d'occuper un lieu pour accueillir la famille, ce qu'ont refusé les membres d'Abraham Mazel ${ }^{15}$. Globalement, les membres de l'association ont tempéré les volontés des militants. En retour, ceux-ci ont apporté d'autres méthodes, modes d'action et insufflé un souffle plus politique à l'accueil.

Le collectif Solidarité migrants Cévennes de Saint-Jean-du-Gard est un exemple de collectif complexe. L'accueil des personnes exilées a permis à des groupes de se rencontrer et d'échanger autour d'un projet commun, ce qui était, si l'on en croit les propos des personnes interrogées, assez inattendu ${ }^{16}$.

\section{Les structures sociales et religieuses, des supports pour l'accueil}

\section{Les lieux du protestantisme au service de l'accueil}

20 Les lieux du protestantisme sont visibles dans les paysages cévenols. Les vallées cévenoles comptent des espaces mémoriels (c'est le cas du musée du désert à Mialet, entre Saint-Jean-du-Gard et Alès, qui retrace l'histoire du protestantisme en Cévennes) et surtout de nombreux temples. Les temples, présents sur la place principale de chaque ville et villages des Cévennes gardoises, sont des lieux protéiformes, à la fois lieux de culte et lieux de la vie culturelle ${ }^{17}$. 
Photographie 1 : Piliers du temple de Lasalle, bâtiment cultuel à forte emprise, sur la place principale du village

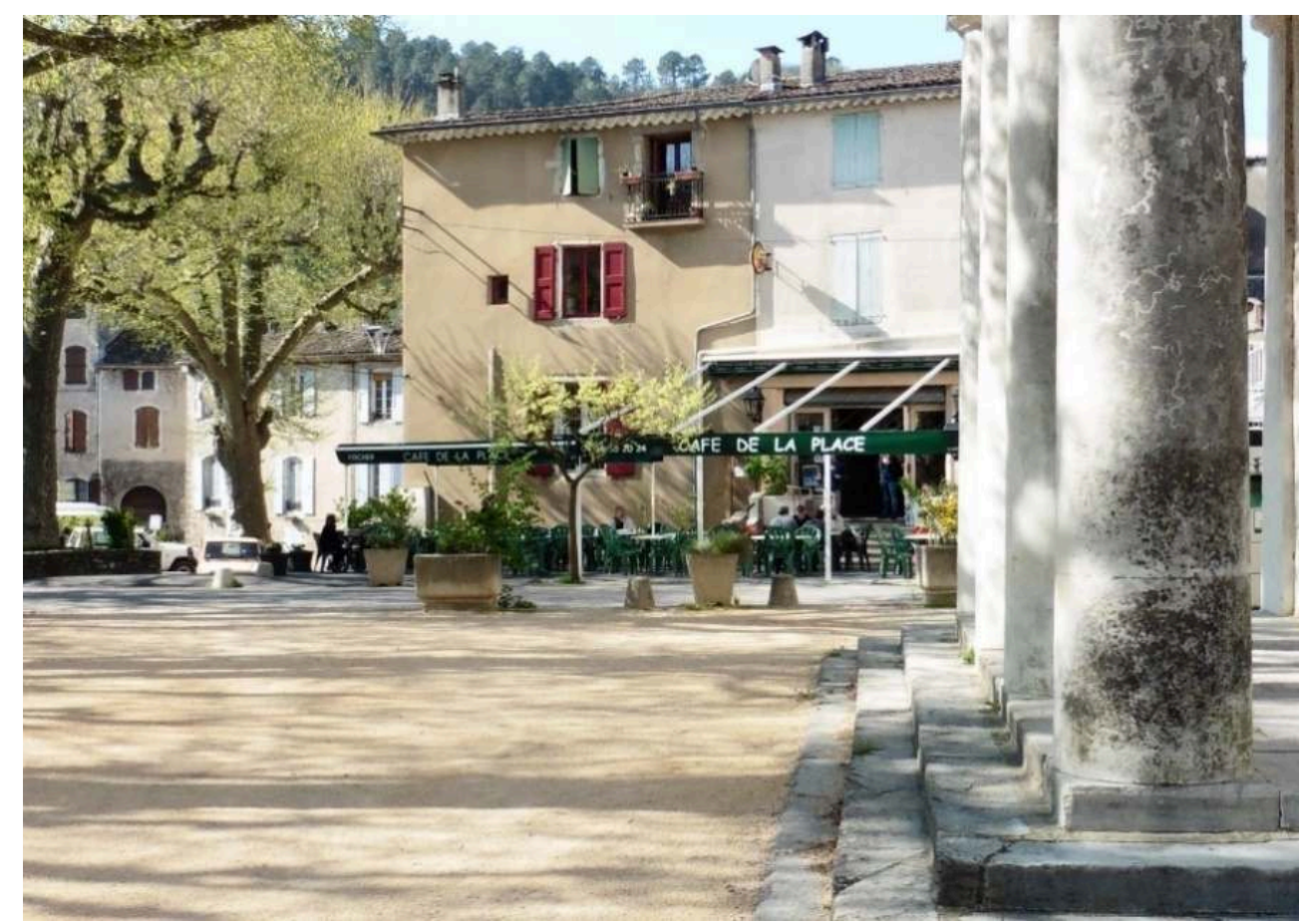

Réalisation : Élise Martin, 2019

21 Les presbytères, normalement lieux de vie des pasteurs, apparaissent particulièrement centraux dans l'accueil des exilés. Ils changent d'usage et sont transformés en salles de réunion pour les collectifs ou lieux de vie pour des familles exilées.

À Saint-Jean-du-Gard, le presbytère fait office de lieu de réunion pour le collectif Solidarité migrants Cévennes. Une dizaine de personnes (membres des restos du Cœur, du centre socio-culturel «l'Oustal», du groupe Cévennes sans frontières et de l'association Abraham Mazel) se regroupent autour de la grande table de la pièce principale du presbytère pour faire des points réguliers sur la situation des familles accueillies. Le presbytère est situé dans un espace central de Saint-Jean-du-Gard puisqu'il se trouve le long de la "Grand Rue », axe qui traverse la petite ville du Nord au Sud. Le lieu est accessible aux bénévoles mais aussi aux familles exilées concernées qui assistent parfois aux réunions.

À Lasalle, les lieux du protestantisme, comme la conciergerie (jouxtant le temple visible sur la photographie 1) et le presbytère, hébergent régulièrement des familles exilées, au moins dans les premiers temps de l'accueil. La situation géographique du presbytère, une grande maison avec jardin située dans la rue principale du village, facilite l'accès aux commerces, écoles et services (Martin 2020).

\section{Un maillage associatif du territoire qui facilite l'accompagnement des exilés}

Quels que soient leur taille et leur nombre d'habitants, les villes et villages accueillants ont pour point commun de compter un très grand nombre d'associations. À titre d'exemple, une ville comme Lasalle, qui recense 1140 habitants, ne compte pas moins 
de 60 associations $^{18}$. Les collectifs d'accueil peuvent compter sur ces nombreuses associations locales actives et polyfonctionnelles. On trouve dans quasiment chacune des villes et chacun des villages concernés par l'accueil des associations qui fournissent de la nourriture (associations connues et conventionnelles et collectifs et réseaux d'entraide informels), des vêtements (plusieurs villages et villes disposent d'une friperie ou d'une boutique solidaire) ou encore des meubles à des sommes modiques. Les personnes exilées s'y rendent au même titre que d'autres personnes en situation de précarité.

À Lasalle par exemple, l'association protestante propose toutes sortes d'objets à la vente dans une brocante (meubles, vêtements, livres, jouets), ce qui permet aux personnes disposant de peu de moyens de s'équiper à moindre coût (photographies 2, 3, 4). À Saint-Jean-du-Gard, les personnes exilées se rendent aux Restos du Cœur (photographie 5) ou encore à l'épicerie solidaire où ils obtiennent de la nourriture grâce à des « bons d'achat » délivrés par la Croix-Rouge ${ }^{19}$. Au Vigan, pas moins de trois associations proposent des denrées alimentaires aux personnes avec un reste à vivre faible ${ }^{20}$ : le Secours Populaire, les Restos du Cœur et une épicerie solidaire (photographie 6). À écouter les personnes interrogées, les associations présentes dans les territoires, qu'elles soient nationales (Secours Populaire, Restos du Cœur, Croix Rouge) ou locales (associations protestantes, magasins solidaires), ne font pas double emploi mais se complètent. Elles font office de supports et de socles (Regourd, 2007) sur lesquels les collectifs peuvent s'appuyer et compter pour proposer un accompagnement complet aux exilés.

Photographies 2, 3, 4 : Brocante de Lasalle tenue par l'association protestante du village, où se rendent les familles exilées accompagnées

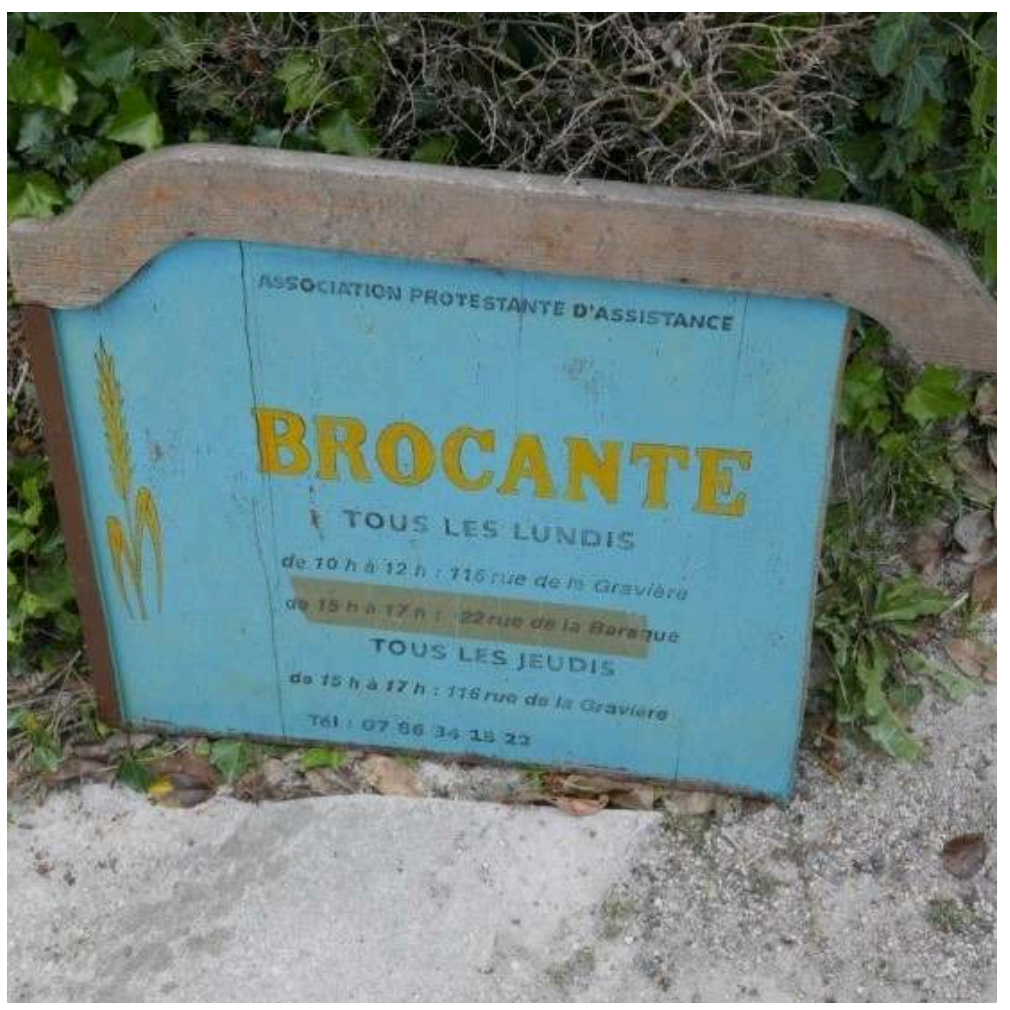

(c) Élise Martin, 2019 


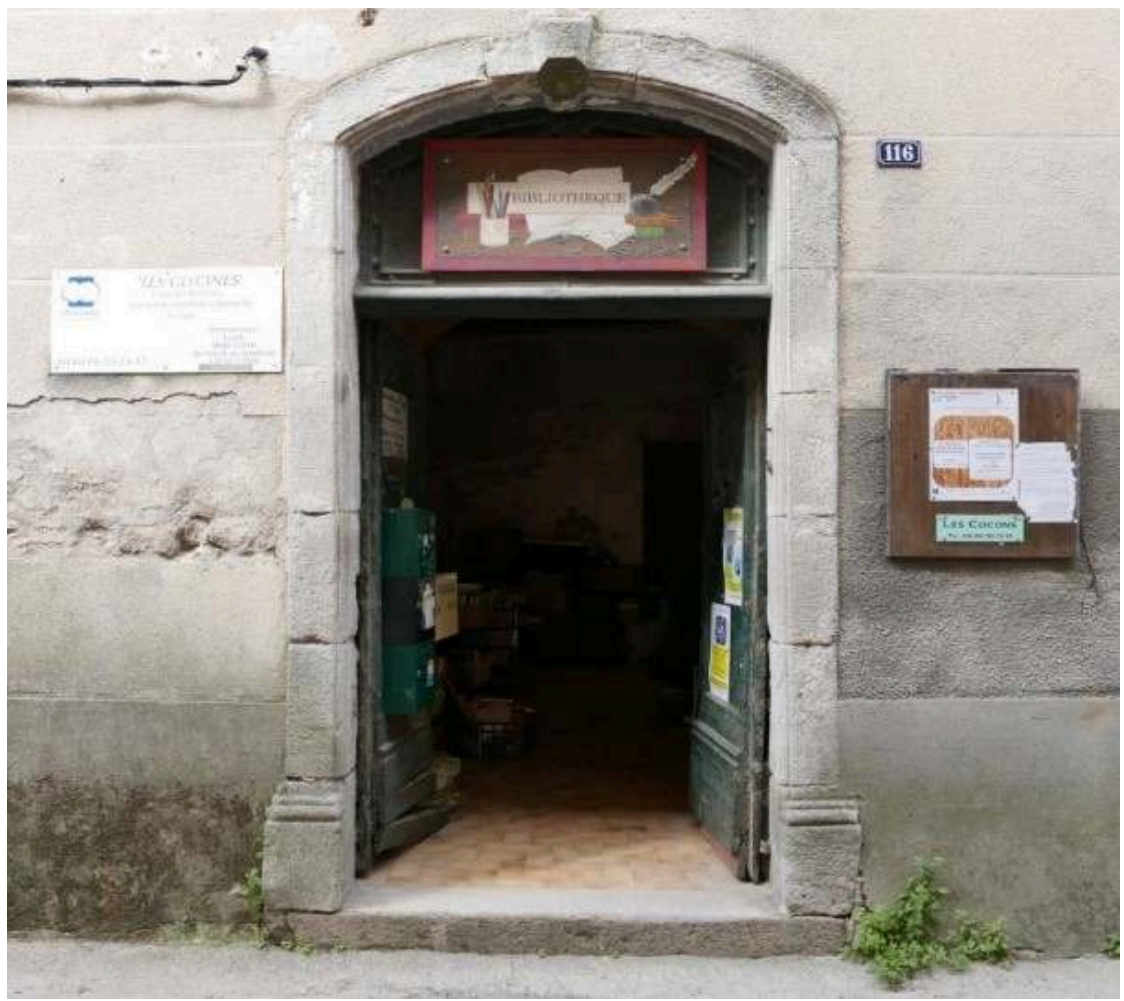

(c) Élise Martin, 2019

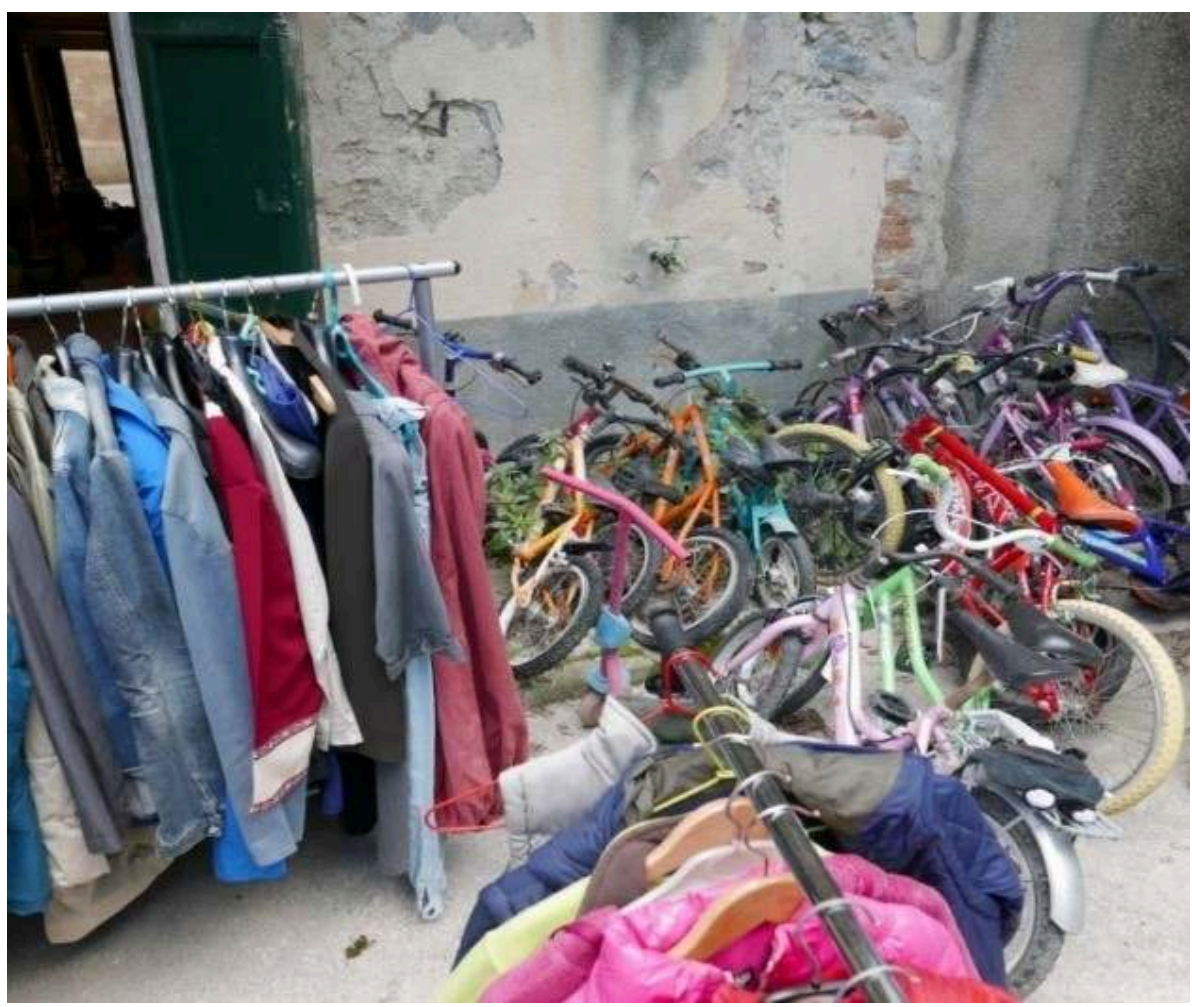

(c) Élise Martin, 2019 
Photographie 5 : Local des Restos du Cœur de Saint-Jean-du-Gard, situé dans la rue principale

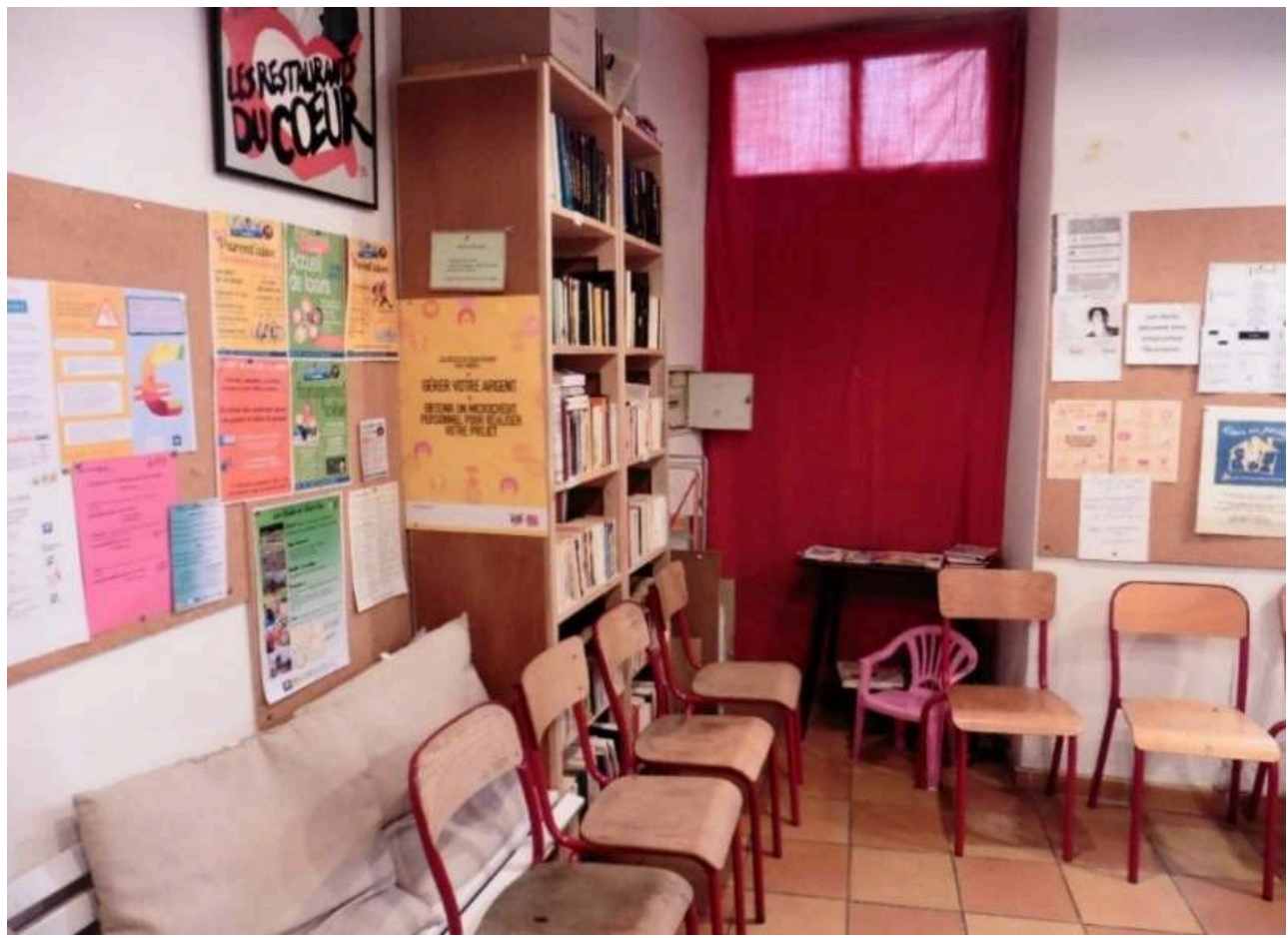

(c) Élise Martin, 2017

Photographie 6 : Épicerie solidaire du Vigan qui partage ses locaux avec l'association protestante de la ville

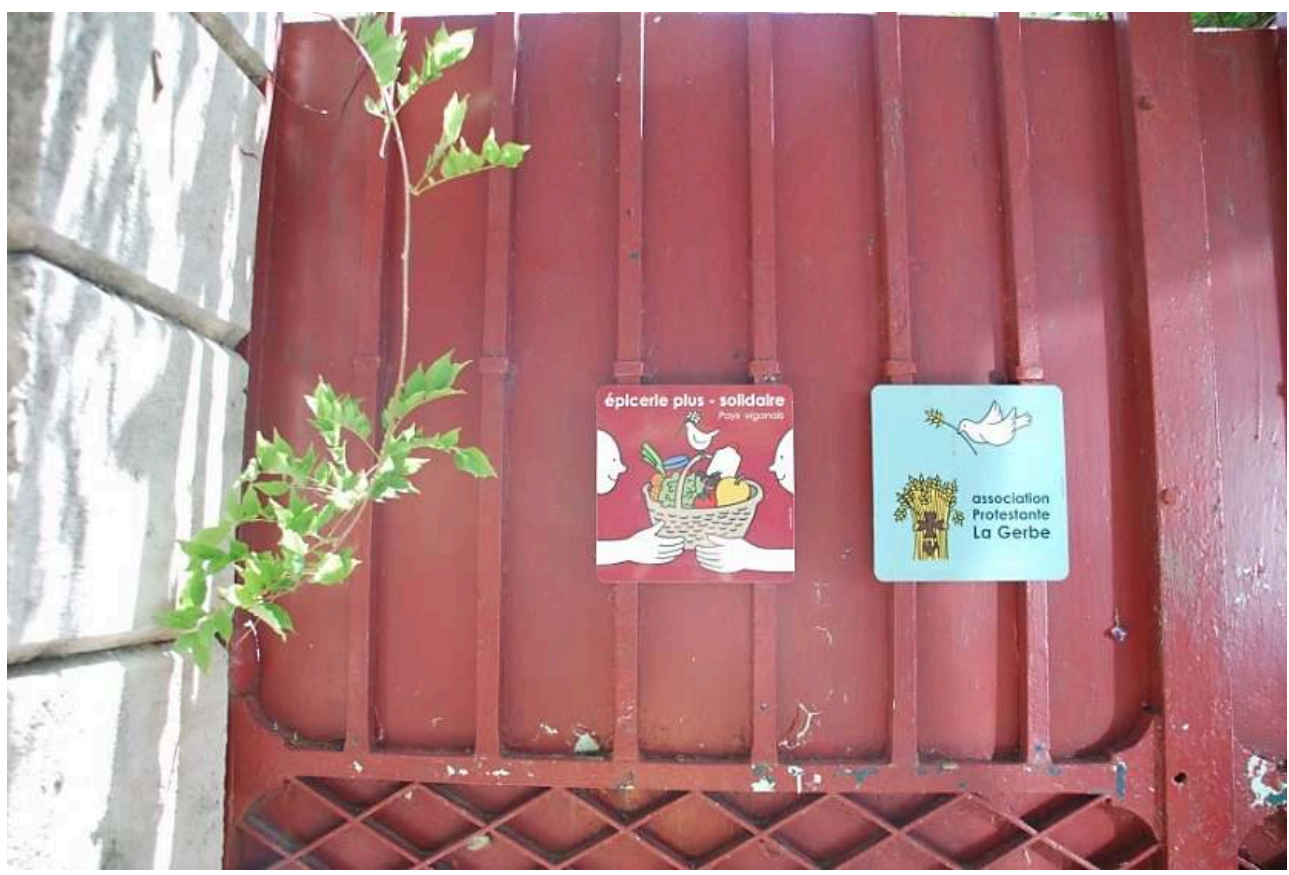

(c) Élise Martin, 2019.

L'accueil des exilés dans les villes et villages cévenols ne relève pas du hasard. L'accompagnement de ces derniers est facilité par l'existence de structures associatives préexistantes dans ces territoires ruraux, dont de nombreuses associations d'aide 
sociale. Les personnes accueillies viennent simplement élargir le panel des bénéficiaires des différentes associations, ce qui ne demande pas nécessairement de créer des structures ad hoc.

\section{De l'engagement individuel aux réseaux de collectifs}

\section{Les acteurs de l'hospitalité : des citoyens engagés avec un fort capital spatial}

Les collectifs rencontrés sur le terrain sont composés de jeunes individus impliqués dans la vie locale mais surtout de retraités (beaucoup d'anciens instituteurs, professeurs, éducateurs, artistes). Ces retraités, personnes ressources pour les territoires ruraux (Blasquiet-Revol, 2018), se divisent en deux groupes : ceux qui se sont installés en Cévennes dans les années 1970-1980 alors qu'ils avaient une trentaine d'années et ceux qui sont arrivés dans les années 1990-2000 pour y passer leur retraite. C'est le cas de Nathalie, enseignante de biologie venue s'installer avec son mari dans le centre-ville de Saint-Jean-du-Gard :

Moi je viens ici depuis qu'suis née. Nous on aime bien ici, justement je m'y reconnais bien quoi. Tu vois nous on a habité des tas de villages, un peu partout, en Bretagne, dans le Poitou, vers Béziers (entretien 6).

L'étude approfondie des trajectoires biographiques des membres des différents collectifs fait ressortir des régularités qui expliquent la propension à accueillir des étrangers. Même si leur capital social diffère, les individus interrogés possèdent pour la plupart un certain capital spatial ${ }^{21}$. C'est le cas de Martine qui accueille des personnes dans sa maison isolée au milieu des montagnes :

Moi j'ai voyagé deux fois 14 mois-là récemment ces cinq dernières années, ça m'a fait pas mal réfléchir à cette thématique quoi (entretien 7).

La sensibilisation à une culture étrangère particulière peut amener toute une vallée à accueillir une population précise. La vallée de Lasalle accueille par exemple des personnes afghanes depuis une dizaine d'années. Cela s'explique par l'intérêt et la sensibilisation de plusieurs habitants de la vallée à la culture afghane (Martin, 2020).

Globalement les entretiens menés avec les membres des collectifs témoignent de modes de vie fondés sur une forte mobilité. C'est le cas par exemple de Nathalie dont les enfants vivent au Burkina Faso et dans les montagnes japonaises :

On a des enfants un peu baroudeurs mais c'est vrai que nous on a toujours bougé. Et on a emmené les trois enfants, ils n'avaient pas peur de bouger c'était inclus dans le truc tu vois... Ils aiment bien (entretien 6).

Certaines personnes continuent à être mobiles une fois la retraite arrivée, en vivant une partie de l'année dans les Cévennes et une autre dans un pays européen limitrophe. C'est le cas de la présidente de l'association Abraham Mazel, ancienne professeure de français et d'histoire-géographie qui vit une partie de l'année près de Saint-Jean-duGard et l'autre à Liège en Belgique :

J'viens dans les Cévennes depuis 1988 parce que mon ex-mari avait une maison aux Plantiers, en 1992 il a eu une pré-retraite donc on a habité là entre 1992 et 2001. En 
2001 je suis retournée en Belgique quatre ans m'occuper de mes parents et je voulais absolument revenir ici, je venais quinze jours à Pâques, je venais deux mois l'été, puis quand j'ai connu Pierre, on a pris une location, il a été d'accord de vivre ici six mois, et puis comme on était bien et que c'était confortable, on est là tout le temps, on va un mois en Belgique (entretien 4).

L'étude des trajectoires biographiques des membres des collectifs montre qu'ils s'investissent pour certains depuis longtemps dans l'accompagnement de personnes exilées. Plusieurs bénévoles rencontrés sont impliqués à RESF (Réseau Éducation Sans Frontières), association particulièrement active dans le Gard qui aide les familles avec des enfants scolarisés dans leurs démarches administratives. Certaines personnes ont aussi consacré plusieurs mois voire années de leur vie à l'accompagnement des exilés, à l'instar de Suzanne du collectif de Lasalle qui raconte plusieurs épisodes de sa vie aux côtés de demandeurs d'asile :

Pendant trois ans j'ai été beaucoup à Sangatte quand y avait encore le hangar, j'ai vu le démantèlement du hangar, j'ai vu les chasses à l'homme dans les dunes etc., je suis une des témoins de ça [...]. J'suis allée vivre à Bruxelles et là avec [une amie] [...] on a créé - dans l'enceinte du lieu d'accueil "le Petit château " ${ }^{22}$, un endroit où y avait 1500, 2000 personnes et peut-être [seulement] 100 femmes et absolument rien pour [elles] - un salon des femmes où deux après-midis par semaine on s'retrouvait pour faire plein de choses (entretien 8).

Les membres des collectifs ont enfin comme point commun d'être engagés plus largement dans la défense de plusieurs causes: certains disent s'inscrire depuis longtemps dans des associations qui militent pour la dignité et le respect des droits humains (Amnesty International) ou encore la défense de l'environnement (les Amis de la Terre). D'autres se sont investis plus récemment dans la lutte contre la construction de l'aéroport Notre-Dame-des-Landes ou encore celle des Gilets jaunes.

Les parcours biographiques des personnes qui forment les collectifs (leur passé engagé, leur propension à s'engager dans diverses causes simultanément) ne sont pas spécifiques aux militants des Cévennes. Christophe Imbert et William Berthomière ont montré que les accueillants ariégeois avaient des profils sensiblement similaires (Berthomière, Imbert, 2019). La singularité des collectifs des Cévennes - a fortiori gardois - réside dans la forte implication des membres de la communauté protestante ${ }^{23}$. Ceux-ci sont actifs dans l'accueil des exilés et sont même parfois à l'initiative de l'accueil comme cela a été le cas à Lasalle (Martin, 2020). Néanmoins, il paraît important de préciser que tous les protestants ne sont pas partie prenante de l'accueil ni même favorables à celui-ci. Les propos de la présidente d'Abraham Mazel nous invitent à nuancer l'implication des membres de la communauté :

Au conseil municipal y a des gens non protestants et athées qui me disent comment est-ce que ça se fait que les protestants qui sont au conseil municipal aient refusé la charte [des communes solidaires]? Je sais ce que je vais dire à la dame: y a des protestants au conseil municipal mais c'est pas nécessairement pour ça des chrétiens, ce sont des protestants sociologiques tu vois ils disent qu'ils sont protestants parce $q u$ 'ils sont de grandes familles protestantes ... (entretien 4). 


\section{Un territoire solidaire interconnecté} centrée sur les vallées. Les bénévoles, les membres des collectifs vivent dans le village où sont accueillis les exilés ou dans les alentours directs et il est rare qu'une personne s'implique au quotidien dans une autre vallée que celle où elle vit. La topographie rallonge les temps de parcours, les personnes mettent beaucoup de temps pour parcourir quelques kilomètres. Les actions politiques et de sensibilisation sont, elles aussi, menées localement. Le parrainage républicain, qui entérine l'entrée symbolique de la personne étrangère dans la communauté des citoyens français, scelle avant tout l'acceptation dans la population locale des exilés accueillis. Cet acte a d'autant plus de sens à l'échelle locale qu'il implique le maire de la commune et l'affiche en tant que responsable politique favorable à l'accueil ${ }^{25}$.

D'autres actions fédèrent la population autour des exilés à l'échelle de la commune. C'est le cas des cantines solidaires: une famille ou un couple prépare des plats de son pays et les partage avec les participants, souvent sur le principe du prix libre. Ce mode d'action simple permet aux accueillis de ne plus être perçus comme les simples bénéficiaires d'une aide extérieure mais comme des acteurs de la vie locale. Nathalie 
donne une description détaillée des cantines solidaires organisées par des membres de Cévennes sans Frontières pour le collectif Solidarité migrants Cévennes de Saint-Jean-duGard :

Ils [le groupe de militants] s'investissent beaucoup dans ce qu'ils appellent des cantines, c'est faire faire des repas par les familles sans papiers, et après on convie les gens à venir manger à prix libre. On déduit ce qui a été acheté pour faire le repas et après toute la somme est donnée aux familles... À l'automne on a fait une cantine ici, qui a super bien marché, on a eu 200 personnes, plus de 200 personnes, des gens improbables de St-Jean qui sont venus j'étais très sidérée, c'était bien. On l'a fait une seule fois parce que c'est beaucoup d'investissement (entretien 6).

Les cantines solidaires sont des catalyseurs de rencontres entre la population gardoise et les exilés. De plus en plus, celles-ci ont lieu en dehors de la vallée de Saint-Jean-duGard, une fois par mois dans un local disposant d'une cuisine, d'une bibliothèque et d'une pièce pouvant accueillir plusieurs dizaines de personnes à Alès. Le principe des cantines solidaires permet au collectif de se faire connaitre et donc de recruter de potentiels soutiens, et aux personnes exilées d'élargir leur cercle de connaissances audelà du village.

Photographie 7 : Affiche collée dans la rue principale de Saint-Jean-du-Gard, invitant les habitants à une cantine solidaire

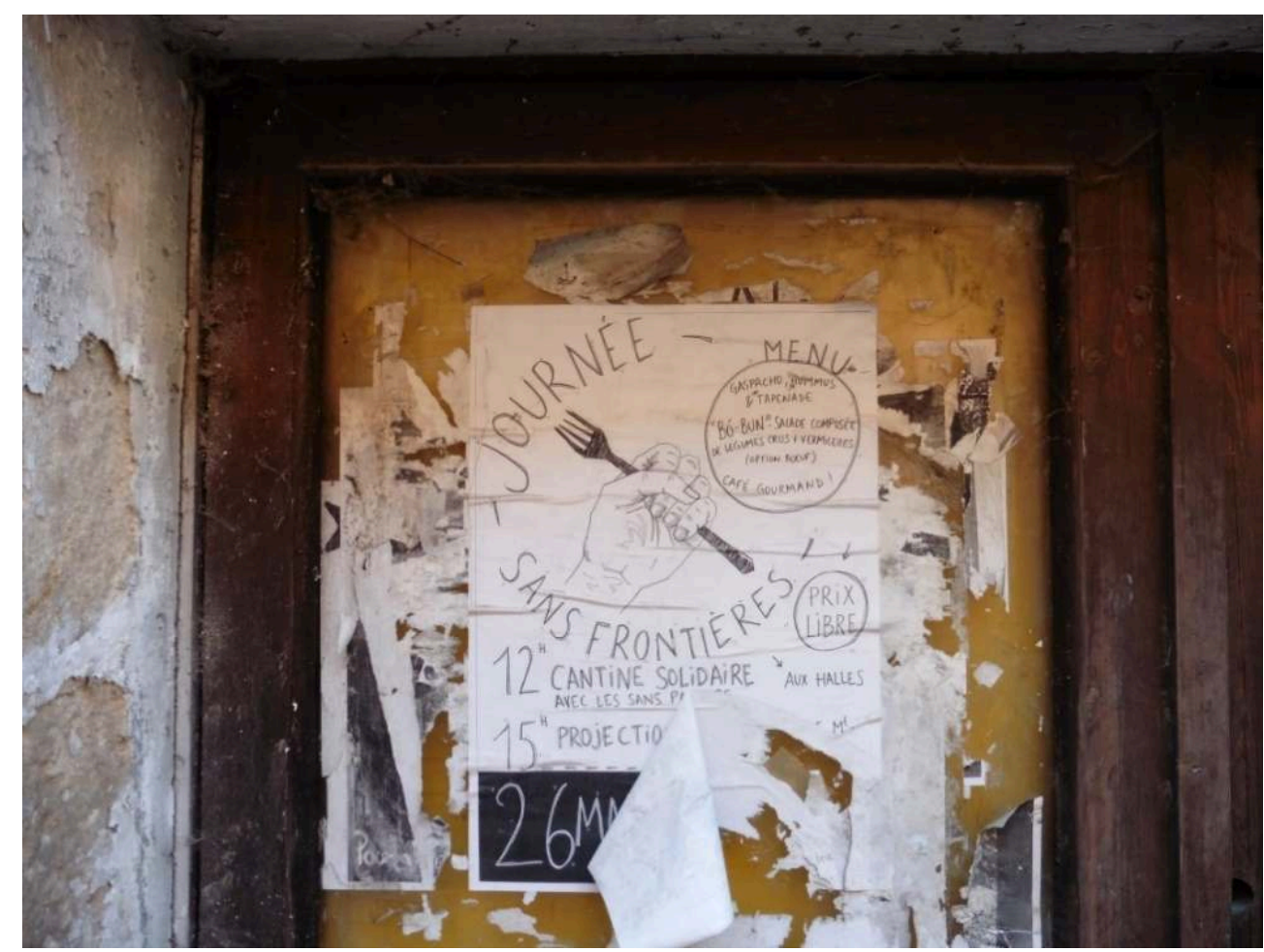

Réalisation : Élise Martin, 2019

Des actions de plus grande envergure permettent de fédérer les membres des divers collectifs et aux accueillants de se rencontrer. L'enquête de terrain montre que les différents collectifs quittent régulièrement les vallées cévenoles pour participer à des manifestations dans la plaine languedocienne. On les retrouve dans des manifestations qui ont lieu devant les préfectures de Nîmes et Montpellier ${ }^{26}$, devant l'Office français de l'immigration et de l'intégration (OFII) à Montpellier ${ }^{27}$ ou encore devant le centre de 
rétention administrative (CRA) de Sète ${ }^{28}$. Il arrive même à certaines associations ou intercollectifs d'envoyer un représentant à Toulouse ou encore à Paris lors de manifestations régionales ou nationales.

\section{Conclusion}

L'engagement de dizaines de personnes, la circulation des membres des collectifs et des informations ont favorisé l'émergence d'un maillage d'initiatives liées à l'accueil d'exilés dans les Cévennes. Les collectifs citoyens se concentrent sur des actions à l'échelle locale (d'un village, d'une vallée) en accompagnant les personnes au quotidien et en sensibilisant les habitants de leur commune à l'exil. Ces groupes informels s'organisent en association ou en intercollectif pour renforcer leur poids et leur visibilité à l'échelle du département et ainsi, dépasser la contrainte de l'isolement géographique. Les personnes engagées dans les collectifs cévenols se distinguent par la permanence et la continuité de leur engagement puisque l'enquête montre que les collectifs sont constitués des mêmes membres actifs depuis leur création en 2015, 2016 ou 2017. À leur échelle, ces habitants engagés contribuent à tisser un solide réseau d'accueil dans un territoire de moyenne montagne aux paysages paradoxalement fermés et hostiles, et font du piémont cévenol une forteresse solidaire.

\section{BIBLIOGRAPHIE}

Babels (2018) Entre accueil et rejet : ce que les villes font aux migrants, Lyon, Le passager clandestin, $120 \mathrm{p}$. (Bibliothèque des frontières).

Babels (2019) Hospitalité en France : Mobilisations intimes et politiques, Lyon, Le passager clandestin, 156 p. (Bibliothèques des frontières).

Barone, Anastasia (2018) Le long été de Vintimille : auto-organisation et criminalisation de la solidarité à la frontière franco-italienne, Mouvements, vol. 93, nº 1, pp. 173-179, réf. du 03/04/2020 [Disponible sur Internet].

Boudou, Benjamin (2018) De la ville-refuge aux sanctuary cities : l'idéal de la ville comme territoire d'hospitalité, Sens-Dessous, vol. 21, n 1, pp. 83-89, réf. du 30/04/2020 [Disponible sur Internet].

Belmessous, Fatiha ; Roche, Élise (2018) Accueillir, insérer, intégrer les migrants à la ville, Espaces et sociétés, vol. 172-173, n 1, pp. 7-18, réf. du 03 avril 2020 [Disponible sur Internet].

Berthomière, William ; Imbert, Christophe (2019) Quand s'engager ancre et s'ancrer « engage » : les voies plurielles de l'autochtonie au sein des réseaux d'aide aux exilés en Ariège, L'Espace Politique, vol. 38, n² 2, réf. du 03 avril 2020 [Disponible sur Internet].

Blasquiet-Revol, Hélène et al. (2018) Ces retraités qui participent à la dynamique locale en milieu rural, Gérontologie et Société, vol. 233, n 1, pp. 71-79, réf. du 03 avril 2020 [Disponible sur Internet]. 
Brault, Marguerite ; Daccord, Hélène ; Lenouvel, Julie (2018) Les lieux de l'insertion et de l'intégration sociale des réfugiés. Le cas de Dessau, ville en décroissance, Espaces et sociétés, vol. 172-173, n 1, pp. 55-72, réf. du 03 avril 2020 [Disponible sur Internet].

Brugère, Fabienne ; Le Blanc, Guillaume (2017) La fin de l'hospitalité. Lampedusa, Lesbos, Calais... Jusqu'où irons nous? Paris, Flammarion, 240 p.

Clavairolle, Françoise (2011) La Borie sauvée des eaux. Ethnologie d'une émotion patrimoniale, Paris, Lahic ; DPRPS-Direction des patrimoines, 292 p. (les Cahiers du Lahic ; 7) [Disponible sur Internet] Dahdah, Assaf ; Audren, Gwenaëlle ; Bouillon, Florence (2018) La ville (in)hospitalière : parcours scolaire et résidentiel d'une famille syrienne à Marseille, Espaces et sociétés, vol. 172-173, nº 1 , pp. 73-91, réf. du 10 février 2020 [Disponible sur Internet].

Gerbier-Aublanc, Marjorie (2018) Un migrant chez soi, Esprit, $n^{\circ} 7 / 8$, pp. 122-129, réf. du 03 avril 2020 [Disponible sur Internet]

Gerbier-Aublanc, Marjorie ; Masson Diez, Evangéline (2019) Être accueilli chez l'habitant : de l'hébergement-épreuve à la cohabitation-tremplin pour les migrants, Rhizome, vol. $71, \mathrm{n}^{\circ} 1$, pp. 51-60, réf. du 03 avril 2020 [Disponible sur Internet]

Gilbert, Margaret (1989) On Social Facts, London, New York, Routledge, 521 p.

Hanappe, Cyrille (2018) La Ville Accueillante. Accueillir à Grande-Synthe. Questions théoriques et pratiques sur les exilés, l'architecture et la ville, Paris, édition du PUCA, 518 p.

Kaufmann, Laurence (2010) Faire « être collectif » : de la constitution à la maintenance, Raisons pratiques, vol 20, pp. 331-372.

Lévy, Jacques ; Lussault, Michel (2003) Capital spatial, Dictionnaire de la géographie et de l'espace des sociétés, Paris, Belin, pp. 124-126.

Louis, Camille (2017) City Plaza, ce que peut encore dire l'hospitalité, Plein droit, n 113, pp. 28-31, réf. du 03 avril 2020 [Disponible sur Internet].

Martin, Élise (à paraître en 2020), Reprendre son souffle dans un village cévenol. Ethnogéographie de l'accueil de personnes migrantes en milieu rural, Revue Européenne des Migrations Internationales.

Masson Diez, Évangeline (2018) Militants, bénévoles, citoyens solidaires. Comment se nommer lorsque l'on vient en aide aux migrants ?, Journal des anthropologues, Hors-série :2018, pp. 159-180, réf. Du 03 avril 2020 [Disponible sur Internet].

Regourd, Estelle (2007) Les associations culturelles, porteuses de projet pour de nouvelles ruralités ?, Norois, $\mathrm{n}^{\circ}$ 204, pp. 67-78, réf. du 03 avril 2020 [Disponible sur Internet]

Searle, John (1995) The Construction of Social Reality, London, Allen Lane ; The Penguin Press, XIII-241 p.

Tarrius, Alain (2014) Quand les territoires circulatoires des transmigrants traversent des quartiers enclavés de villes moyennes françaises, Revue Européenne des Migrations Internationales, vol. 30, $\mathrm{n}^{\circ}$ 2, pp. 169-192, réf. du 03 avril 2020 [Disponible sur Internet].

Documents officiels

Circulaire du 20 novembre 2015 relative à la création de centre de mise à l'abri pour les migrants de Calais, Ministère de l'intérieur, Ministère du logement, de l'égalité des territoires et de la ruralité, 20 novembre 2015

https://www.gisti.org/IMG/pdf/151120-circ-centre-mise-abri-calais-1.pdf 
Sources journalistiques

(2017) 12 réfugiés politiques soudanais parrainés au Vigan pour éviter leur expulsion, France 3 Occitanie, 5 juillet 2017, réf. du 03 avril 2020

https://france3-regions.francetvinfo.fr/occitanie/12-refugies-politiques-soudanais-parrainesau-vigan-eviter-leur-expulsion-1292121.html

(2017) Manifestation de soutien aux migrants devant la préfecture de Montpellier, France bleu, 18 décembre 2017, réf. du 03 avril 2020

https://www.francebleu.fr/infos/societe/les-militants-devant-la-prefecture-de-montpellier-ensoutien-aux-migrants-1513623118

(2018) Migrants : manifestation des policiers et des "antis" devant le centre de rétention de Sète, Midi libre, 22 juin 2018, réf. du 03 avril 2020

https://www.midilibre.fr/2018/06/22/migrants-manifestation-des-policiers-et-des-antis-devantle-centre-de-retention-de-sete,1690721.php

(2019) Montpellier : des migrants manifestent pour leur droit à être hébergés, Midi libre, 12 juin 2019, réf. du 03 avril 2020

https://www.midilibre.fr/2019/06/12/montpellier-des-migrants-manifestent-pour-leur-droit-aetre-heberges,8252539.php

(2019) Cévennes Terre d'Accueil aide actuellement dix-sept réfugiés, Midi libre, 30 septembre 2019, réf. du 03 avril 2020

https://www.midilibre.fr/2019/09/30/cevennes-terre-daccueil-aide-actuellement-dix-septrefugies, 8447042.php

Sites internet

Site de la mairie de Lasalle : http://www.museedudesert.com/article5684.html

Site des communes solidaires du Gard : http://communessolidairesgard.collectif-citoyen.fr/ charte-des-communes-solidaires/

Site de l'association Abraham Mazel : http://www.abrahammazel.eu/

Site du collectif Cévennes sans frontières : https://cevennessansfrontieres.noblogs.org/

\section{NOTES}

1. Les Cévennes ont été un lieu de refuge pour les protestants au XVIe siècle, pour certains républicains exilés pendant la guerre d'Espagne (1936-1939) et pour des juifs pendant la Seconde Guerre mondiale.

2. Des bus assurent des liaisons régulières entre Le Vigan et Montpellier (1h de route), et entre Saint-Jean-du-Gard et Nîmes (1h de route).

3. Le tableau ne mentionne pas les accueils antérieurs à 2015. Lasalle ou Mialet accueillent, par exemple, des exilés depuis plus longtemps.

4. Le maire de cette commune a d'ailleurs signé la charte «commune solidaire du Gard ». Les maires de Monoblet et Mandagout ont fait de même. http://communessolidairesgard.collectifcitoyen.fr/charte-des-communes-solidaires/

5. Une circulaire des ministres de l'Intérieur et du Logement du 20 novembre 2015 entérine la création des $\mathrm{CAO}$ et définit ces lieux comme des lieux où les personnes pourront « redéfinir leur projet migratoire et renoncer à rejoindre illégalement le Royaume-Uni ».

6. Aujourd'hui, seuls les CAO du Vigan et Saint-Hippolyte-du-Fort existent encore. 
7. La taille est très variable selon celle des villages et villes. Les collectifs peuvent compter entre 5 et 10 membres actifs comme 20 ou 30.

8. On note la récurrence du choix des mots « solidarité » et « accueil ».

9. Crée à l'initiative de l'APA (Association Protestante d'Assistance), le réseau ANAIS (associations nîmoises d'actions et d'interventions sociales) coordonne 47 associations et acteurs sociaux dans le Gard.

10. Des habitants de toute la vallée des Gardon de Mialet et Saint-Jean-du-Gard se sont mobilisés contre le projet de barrage, projet qui aurait abouti à la bétonisation d'une vallée sauvage aux paysages forestiers fermés : Mazel est sorti de là, l'association. Y avait des gens qui étaient très impliqués dedans, ça a soudé les gens et ils ont eu envie de continuer à faire des choses pour plutôt que des choses contre, c'est comme ça que l'association a été créée en 1992. Ils ont acheté la maison [d'Abraham Mazel] en ruine en 1995 (entretien 4).

11. La maison d'Abraham Mazel, camisard cévenol, est un lieu à l'empreinte mémorielle forte puisqu'elle a successivement abrité des camisards au XVIIe siècle et des maquisards pendant la Seconde Guerre mondiale.

12. http://www.abrahammazel.eu/contact/lassociation/nos-objectifs/

13. De nombreuses initiatives solidaires et militantes ont eu lieu à l'été 2015 à la frontière francoitalienne.

14. https://cevennessansfrontieres.noblogs.org/

15. On observe une importante différence d'âge entre les deux groupes comme en témoignent les propos de Nathalie, membre d'Abraham Mazel et du collectif Solidarité Migrants Cévennes: Eux, ils se sont dit au départ oh tous ces vieux [...] Puis ils ont appris à nous connaitre, à voir qu'on avait été des militants quand on était beaucoup plus jeunes, qu'on a fait beaucoup de choses, et qu'en fait ça va, on sait de quoi on parle (entretien 6).

16. On a pu rassembler des gens, y compris les anarchistes qu'on a mis avec la paroisse protestante, c'est merveilleux (entretien 4).

17. Des concerts et la projection de films y ont lieu, notamment lors du festival du film documentaire de Lasalle.

18. Chiffres visibles sur le site officiel de la mairie https://www.lasalle.fr/vie-culturelle-etassociative

19. Les associations travaillent ensemble. C'est un p'tit village, par exemple les gens [sous-entendu les bénévoles] qui s'occupent des restos du cour c'est des gens qui sont aussi adhérents à Mazel, qui connaissent l'Oustal, les gens des Restos du Cour ils connaissent l'Oustal. Tout le monde se connait (entretien 4).

20. Le reste à vivre est ce dont un foyer dispose pour vivre un mois, une fois les charges fixes payées.

21. Soit « l'ensemble des ressources, accumulées par un acteur, lui permettant de tirer avantage, en fonction de sa stratégie, de l'usage de la dimension spatiale de la société. » (Levy, Lussault, 2003).

22. Le Petit-Château à Bruxelles est une ancienne caserne qui a été transformée en lieu d'accueil pour demandeurs d'asile en 1986. Il est aujourd'hui géré par la FEDASIL (Agence Fédérale d'Accueil pour les Demandeurs d'Asile), instance sous la tutelle du secrétariat d'Etat à l'Asile et à la Migration belge.

23. La limite historique entre les Cévennes dites catholiques et les Cévennes protestantes se situe au Pont-de-Montvert dans le sud de la Lozère.

24. L'association comptait une centaine d'adhérents et plus de 250 sympathisants en septembre 2019. «Cévennes Terre d'Accueil aide actuellement 17 réfugiés », Midi libre, 30 septembre 2019.

25. Au Vigan, 12 soudanais ont par exemple été parrainés en juillet 2017 par le maire de la commune. " 12 réfugiés politiques soudanais parrainés au Vigan pour éviter leur expulsion ", France 3 Occitanie, 5 juillet 2017. 
26. «Manifestation de soutien aux migrants devant la préfecture de Montpellier », France bleu, 18 décembre 2017.

27. «Montpellier : des migrants manifestent pour leur droit à être hébergés ", Midi libre, 12 juin 2019.

28. "Migrants : manifestation des policiers et des "antis" devant le centre de rétention de Sète ", Midi libre, 22 juin 2018.

\section{RÉSUMÉS}

Depuis la fin de l'année 2015, des collectifs d'habitants abritent, soutiennent et hébergent des personnes exilées dans des villes et villages des moyennes montagnes cévenoles. Ces groupes de taille variable accompagnent localement et quotidiennement des exilés avec l'appui d'associations à caractère social et/ou religieux bien ancrées dans les territoires. Les collectifs, qui s'apparentent à des groupes informels mêlant retraités et jeunes militants, s'organisent en intercollectif pour mener des actions de plus grande envergure et gagner en visibilité. Plusieurs années après la naissance de collectifs citoyens d'accueil en réaction à la médiatisation de «la crise migratoire ", les habitants engagés parviennent à pérenniser leur action et à consolider un vaste et solide réseau de solidarité.

\section{INDEX}

Index géographique : France, Cévennes, Gard, Lozère

Mots-clés : exilés, accueil, action citoyenne, solidarité, milieu rural

\section{AUTEUR}

\section{ÉLISE MARTIN}

Doctorante en géographie, laboratoire ART-DEV (UMR 5281) Université Paul Valéry (Montpellier 3)

elise.martin@ens-lyon.fr 